\title{
ESTRATEGIAS DE LINAJE Y PATRIMONIO EN LA OLIGARQUÍA BAJOMEDIEVAL TUROLENSE: LA PUGNA POR LA ESCRIBANÍA DEL JUSTICIA DE MORELLA
}

Alejandro Ríos Conejero ${ }^{1}$ Universidad Complutense de Madrid

Fecha de recepción: 8 de abril de 2020

Fecha de aceptación: 22 de junio de 2020

\begin{abstract}
Resumen
El objetivo de este trabajo es realizar un análisis de las estrategias familiares llevadas a cabo por la oligarquía turolense durante la Baja Edad Media con el fin de evitar la disgregación de su patrimonio. Para ejemplificar las herramientas usadas por los linajes de esta élite se analizará un bien concreto, las rentas de la escribanía de Morella y sus aldeas, a lo largo de seis generaciones, desde su adquisición en 1328 hasta su enajenación en 1519.
\end{abstract}

\section{Palabras clave}

Oligarquía, estrategias familiares, Baja Edad Media, Teruel, escribanía.

\begin{abstract}
The aim of this article is to analyse the strategies that the Turolean urban oligarchy carried out during the late Middle Ages in order to avoid the disintegration of their patrimony. A specific property is analysed to illustrate the resources used by the lineages of this elite: the assets of the scribe's court of Morella and its villages. The study covers six generations, from its acquisition in 1328 to its alienation in 1519 .
\end{abstract}

\section{Keywords}

Oligarchy, family strategies, late Middle Ages, Teruel, scribe's court.

\section{Résumé}

L'objet de cet article est d'analyser les stratégies familiales établies par l'oligarchie de Teruel à la fin du Moyen Âge dans le but d'éviter la désintégration de son patrimoine. On se centrera sur un phénomène particulier pour illustrer les techniques utilisées par les lignées de cette élite : le

\footnotetext{
1 Universidad Complutense de Madrid, Departamento de Historia de América y Medieval y Ciencias Historiográficas. Facultad de Geografía e Historia, edificio B. Calle Profesor Aranguren s/n, Ciudad Universitaria, 28040, Madrid. Correo electrónico: ariosconejero@ucm.es / ariosconejero@gmail.es. ORCID: https://orcid.org/0000-0002-5224-1813.
} 
revenu du greffe de Morella et de ses villages sur six générations, depuis son acquisition en 1328 jusqu'à son aliénation en 1519 .

\section{Mots clés}

Oligarchie, stratégies familiales, Bas Moyen Âge, Teruel, greffe.

\section{Introducción}

Al estudiar la historia de cualquier ciudad pronto vemos la repetición de unos apellidos concretos en la documentación, ya sea firmando como testigos, realizando compraventas u ocupando diversos cargos en la administración municipal. Estos apellidos se corresponden con un puñado de linajes que forman la oligarquía de ese municipio, y que se caracterizan por poseer un nivel socio-económico elevado y por controlar un importante porcentaje de las rentas y propiedades del lugar.

Simultáneamente, estas familias compartían una mentalidad específica y una forma de vida que tendía a reproducir e imitar la de la clase dominante del feudalismo: la aristocracia. En ese sentido, buscaron alejarse de los menestrales y asemejarse a la nobleza, por lo que rechazaron los trabajos manuales y persiguieron vivir de rentas, tanto desde el punto de vista económico como desde el simbólico. La adopción de estos ideales obligó a estos linajes a guiar muchas de sus acciones por criterios de racionalidad intencional que aumentaran sus rentas e impidieran que su patrimonio se disgregase. Hecho que obligaba a que sus actuaciones estuvieran marcadas por un sistema de reglas sociales, conscientemente elaboradas y aplicadas para conseguir los objetivos propuestos del mejor modo posible. ${ }^{2}$ Idea que entronca con los conceptos desarrollados por M. Harries de que las acciones son racionales y se refieren a sistemas lógico-empíricos cuyas distinciones fenoménicas están hechas de contrastes y discriminaciones que los actores consideran significativos, con sentido, reales o de algún modo apropiadas. ${ }^{3}$

En ese sentido, los linajes pertenecientes a la oligarquía se dotaron de diferentes recursos que les permitieran impedir la disgregación de su patrimonio, o peor, que este cayera en manos de una facción contraria. Lo que en estas páginas se pretende ejemplificar son las estrategias familiares, y en especial los recursos de que disponían las mujeres de la élite, en los siglos XIV y XV para garantizar la perdurabilidad de las posesiones familiares. Para ello se atenderá a las asignaciones de recursos humanos y materiales que determinados linajes dedicaban a actividades relacionadas por el parentesco, ya fuera consanguíneo o afín, y cuyo objetivo era maximizar su adaptación al entorno material y social en que estas familias estaban inmersas. ${ }^{4}$

GoDelier, Lo ideal y lo material, p. 63

Harries, El desarrollo de la teoría, p. 493.

Garrido Medina y Gil Calvo, "El concepto de estrategias familiares", pp. 25-26. 
Con el fin de ilustrar mejor algunas de las estrategias familiares de los linajes de la oligarquía urbana se analizará un bien concreto, la escribanía de Morella y de sus aldeas, así como los métodos llevados a cabo por sus poseedores, en especial mediante la rama femenina de la familia, para asegurar su mantenimiento dentro del linaje. ${ }^{5}$ Regalía que, junto con el señorío de Escriche, fue motivo de disputa entre las dos familias más importantes de la oligarquía turolense: los Sánchez Muñoz y los Marcilla.

La elección de este objeto de estudio concreto corresponde al importante corpus documental que sobre él se conserva en diferentes archivos turolenses, gracias al cual se puede rastrear su pertenencia a una misma familia desde su donación a mediados del siglo XIV por Alfonso IV hasta su enajenación definitiva durante el siglo XVI. La mayor parte de la documentación referente a esta regalía se custodia en el Archivo de la Catedral de Teruel, en donde se guardan privilegios reales que confirman su posesión, pleitos acerca de su propiedad entre diferentes ramas familiares y documentos familiares, como capitulaciones matrimoniales, constituciones de dote o testamentos, en los que se muestran las herramientas de que disponía esta familia para salvaguardar su patrimonio. Junto a estas importantes fuentes también hay que considerar los fondos del Archivo Histórico Provincial de Teruel, en especial los referentes a la familia Sánchez Muñoz-Dolz del Espejo, la documentación del archivo notarial de Morella o varios pliegos procedentes de archivos turolenses que se conservan en el Archivo de la Corona de Aragón y la Biblioteca de Cataluña. ${ }^{6}$

\section{La escribanía del justicia de Morella y Lope de Concud}

En primer lugar, creo conveniente hacer una breve explicación sobre qué se entendía por escribanía y en qué consistía su posesión. El vocablo escribanía hace referencia a un monopolio señorial/real sobre la redacción legal de los documentos que eran expedidos, y por los cuales los particulares pagaban un canon. Existieron diferentes tipos de escribanías donde se redactaban los documentos públicos emanados de diferentes instituciones, tales como los oficiales reales o municipales, los tribunales municipales o los concejos, si bien todas ellas funcionaban de forma similar. Los particulares debían abonar una tarifa dependiendo de la tipología de documento y el señor o el rey tenían derecho a una parte de esa tasa, sin embargo, desde el siglo XIII, era habitual que ese derecho se cediese a terceras personas o a instituciones locales. ${ }^{7}$ Es el caso de muchas

\footnotetext{
Con el fin de facilitar al lector la comprensión del texto se incluye, al final del mismo, el árbol genealógico del linaje analizado.

6 Durante las primeras décadas del siglo XX, los herederos de la baronía de Escriche pusieron a la venta su biblioteca y archivo, siendo adquirida gran parte por el librero Salvador Babra, quien dispersó los fondos entre diferentes particulares e instituciones. Tras distintas vicisitudes parte de estos fondos fueron adquiridos por estas dos instituciones situadas en Barcelona, algunos de los cuales han sido transcritos y publicados por López Rajadel, Vid. López Rajadel, Datación de la historia de los amantes de Teruel; y López RAJADEL, Libro del linaje de los Marcilla.

Verdés Pijuan y Guinot Rodríguez, Voz “Escrivania”, http://www.1minut.info/glosariofiscalidad.org/ wp/?page_id $=41$
} 
de las escribanías relacionadas con los diferentes ámbitos de la administración municipal que, sobre todo en los lugares de realengo, acabaron en manos de los propios concejos. Cesiones de derechos que los diferentes soberanos hicieron a cambio de granjearse la fidelidad de las élites ciudadanas, ya que les permitía disfrutar de una serie de recursos que de otra forma les estarían vedados. ${ }^{8}$

Por otra parte, los soberanos hicieron uso de este tipo de rentas, así como de otros títulos y oficios, para recompensar a gentes de su entorno por su fidelidad o por los servicios que les hubieran prestado. Ejemplo de estas actuaciones son la concesión por parte de Jaime I de las escribanías de Azanuy y de Almudévar a Bernardo de Na Guillerma y a Romeo de Atrosillo respectivamente, ${ }^{9}$ o la que los Reyes Católicos hicieron dos siglos después a Juan Álvarez de Toledo, a quien entregaron la escribanía de la villa de Ponferrada por "consideraçion a los serviçios que nos hizo en el çerco de las vyllas de Vyllafranca y Ponferrada, e los otros lugares del Bierço, e çiertas heridas que en ellos recçebio, a enmienda e remuneraçion dellos". ${ }^{10}$

Estas dádivas eran muy valoradas por la baja nobleza y por los miembros de las élites ciudadanas ya que, en el caso de las escribanías, su posesión estaba disociada de la actividad del escribano. Lo que se traduce en que la adjudicación de una escribanía era en realidad una concesión remunerativa y no una función en la administración, por lo que era muy frecuente que los titulares de estas regalías tuvieran su residencia en otras localidades, o que poseyeran cargos que les dificultase ejercer como escribanos. Problema que se solucionaba con la concesión explícita o implícita de poder designar sustitutos o de arrendarlas al mejor postor. ${ }^{11}$ Por todo ello, estas regalías eran una importante vía de promoción económica, en especial en caso de recibirla de forma vitalicia.

Este tipo de cesiones dieron lugar a la patrimonialización de algunas escribanías, puesto que los beneficiarios gozaban de ellas durante toda su vida, y en el ocaso de esta muchos consiguieron que los soberanos las entregaran en los mismos términos a sus herederos. De esta manera, aunque las escribanías no se integraron nunca en el patrimonio familiar, el disfrute de estas rentas se convirtió en hereditario en múltiples ocasiones. ${ }^{12}$ Ahora bien, existieron algunos casos extraordinarios en los cuales los monarcas cedieron estas rentas a una persona a perpetuidad, por lo que quedaban adscritas a ese individuo y a su descendencia, lo cual hacía que se añadieran al patrimonio familiar como fue el caso de la escribanía de Morella que aquí nos ocupa.

De acuerdo a este sistema de premios que acabamos de ver no es extraño que Alfonso IV decidiera agasajar a uno de sus vasallos, Lope de Concud. La cercanía del citado Lope, habitante de Teruel, y el soberano es incuestionable, puesto que desempeñó

Díez SÁnchez, "La escribanía de la sala del Consell", p. 312.

Cabanes Pecourt, Documentos de Jaime I, pp. 135-136 y 150.

RÁbade OBRado, "Las lugartenencias de escribanías como conflicto", pp. 216-217.

Conde-Francisco Gimeno, "Notarías y escribanías de concesión real", pp. 309-312.

Rodríguez Llopis, “La escritura y el poder”, pp. 16-17. 
diversos oficios dentro de la casa del rey: secretario desde $1325^{13}$, escribano ${ }^{14} \mathrm{y}$ desde 1328 lo encontramos ejerciendo como tesorero real ${ }^{15}$. A lo largo de esos años de servicio el Benigno le entregó diversas recompensas por sus servicios: un tercio de la décima recaudada en Arcos de las Salinas ${ }^{16}$ un esclavo musulmán, ${ }^{17} \mathrm{o}$ un heredamiento y un alodio en la vega del Tajo, en territorio de Albarracín. ${ }^{18}$

Todas esas recompensas pasaron a engrosar la ya de por sí amplia fortuna de Lope de Concud: disponía de diferentes bienes inmuebles en los términos de Teruel, Albarracín y sus aldeas y, desde 1327, poseía el señorío de Escriche. Este señorío, que pertenecía a la familia Varea, estaba constituido por el pequeño municipio de Escriche y una torre fortificada. Fue a un miembro de este linaje, Toda Ruíz de Varea, a quien Lope de Concud le compró el lugar por 42.000 sueldos jaqueses. ${ }^{19}$ Adquisición que incluía el mero y mixto imperio sobre todos los vasallos pertenecientes a este pequeño señorío. ${ }^{20}$ No obstante, ninguno de los premios recibidos por Lope de la Corona se asemejaba a la concesión de la escribanía de la curia del justicia de Morella y sus aldeas, la cual el monarca le entregó a perpetuidad el 26 de marzo de 1328. Puesto que, aunque no tenemos conocimiento de la cuantía exacta de la renta que generaba esta regalía, no debía ser escasa, ya que en esta escribanía no solo se redactaban documentos referidos a la población de Morella, sino también de las querellas de la quincena de aldeas que dependían de esta localidad. Circunstancia que se derivaba de que la villa de Morella ostentaba la jurisdicción civil y criminal sobre las aldeas y, si bien a mediados del siglo XIV estas obtuvieron la potestad de juzgar en pleitos civiles menores, tuvieron que seguir recurriendo al justicia de Morella para pleitos civiles de mayor cuantía o para los criminales. Igualmente, a pesar de los cambios jurisdiccionales ocurridos durante el Trescientos, el justicia de Morella se mantuvo como tribunal de apelación a las sentencias emitidas tanto por los tribunales de la urbe como por los de las aldeas. ${ }^{21}$

Pero, a diferencia de otras mercedes hechas a Lope, esta vez no se trataba de un regalo, sino que esta cesión se hizo a cambio de que Lope renunciara a un legado testamentario entregado por Teresa de Entenza, difunta esposa de Alfonso IV, de 10.000 sueldos barceloneses. Quizá este hecho explicaría que la donación fuese a perpetuidad, mientras que hasta ese momento esta escribanía había sido cedida a diferentes personas únicamente durante dos generaciones, tras lo cual volvía al dominio real. Es el caso de Mateo Paver

\footnotetext{
13 Archivo de la Corona de Aragón (en adelante ACA), Cancillería, Registros, n ${ }^{\circ} 411$, ff. 70 y ss.

14 ACA, Cancillería, cartas reales, Alfonso IV, caja 32, n 3795; ACA, Cancillería, registros, $\mathrm{n}^{\circ}$ 428, fol. 281-281v.

15 ACA, Cancillería, registros, $\mathrm{n}^{\circ} 430$, fol.109-109v.

16 ACA, Cancillería, registros, $n^{\circ} 443$, fol. 51-51v.

17 ACA, Cancillería, cartas reales, Alfonso IV, caja 2, no 161.

18 ACA, Cancillería, cartas reales, Alfonso IV, caja 2, no 194.

19 LóPez RaJAdel, Datación de la historia de los amantes de Teruel, pp. 65-66 y 128-129; López RaJADEL, Libro del linaje de los Marcilla, p. 24.

20 ACA, Cancillería, registros, $\mathrm{n}^{\circ} 428$, fol.24v.

21 Sánchez Adell, "La Comunidad de Morella", pp. 92-102; Royo Pérez, Vilafranca (1239-1412), pp. 71-79; Royo Pérez, Els arrels històriques de la comarca dels Ports, pp. 236-305.
} 
y su heredero o de Arnaldo Cortit y su hijo Guillermo Cortit, quien la disfrutaba cuando fue transferida a Lope de Concud. ${ }^{22} \mathrm{Al}$ no poder ser enajenada mientras viviera su actual dueño, la concesión datada en 1328 no fue efectiva hasta la muerte de Guillermo Cortit, en una fecha que desconocemos.

Sin embargo, Lope nunca llegó a gozar de la renta morellana, pues se enemistó con los monarcas y fue ajusticiado en Valencia en 1331. El origen de esta hostilidad hay que buscarla en el acercamiento de Lope al infante Pedro frente a la amenaza que suponía para él la segunda esposa de su padre, Leonor de Castilla; muestra de la relación entre Lope y el infante es la confianza que el futuro Pedro IV puso en él al nombrarle su procurador en 1329. ${ }^{23} \mathrm{Al}$ mismo tiempo, la política dinástica de Alfonso IV pasaba por desgajar importantes feudos del patrimonio real y entregarlos a los vástagos tenidos con Leonor, en especial Fernando. Este hecho iba en contra de la indivisibilidad de la corona pregonada por Jaime II y jurada por el actual soberano, a la vez que hacía que la aristocracia aragonesa temiera una reducción de sus privilegios asociada a la disminución del realengo. ${ }^{24} \mathrm{De}$ ahí que parte de las villas y ciudades, en especial las situadas en el reino de Valencia, así como un importante grupo de caballeros se opusieron a estas donaciones y se lo hicieron saber a los monarcas, granjeándose la hostilidad de la reina. La crónica de Pedro IV se hace eco de este momento y reconstruye el intercambio dialéctico entre Alfonso IV, la reina Leonor y el representante de los detractores de la política real, Francesc de Vinatea. ${ }^{25}$ Si bien el monarca se retractó y revocó las concesiones hechas al infante Fernando, nada le impidió que impusiera férreas represalias a aquellas personas que con más ahínco se habían opuesto a la enajenación de la hacienda regia. De entre todos ellos, García Lóriz y Miguel Pérez Zapata fueron inculpados, por lo que perdieron su puesto en la corte y debieron huir, pero nada comparado con lo que le ocurrió a Lope de Concud. El secretario real fue encausado por crímenes de lesa majestad, por lo que fue detenido en la localidad turolense de Godos, a donde había huído desde Barcelona, y llevado a Valencia, en donde fue torturado, ajusticiado y todos sus bienes fueron confiscados. ${ }^{26}$

\section{La escribanía de Morella y los herederos de Lope de Concud}

A pesar de la incautación, la Corona se apiadó de los herederos de Lope y con el tiempo les devolvieron gran parte del patrimonio decomisado. No ocurrió lo mismo con las rentas

\footnotetext{
22 Archivo de la Catedral de Teruel (en adelante ACT), perg. 76, doc. 89.

23 ACA, Cancillería, cartas reales, Alfonso IV, caja 6, nº 814.

24 Lafuente Gómez, "Amistad y poder entre la baja nobleza", pp. 1516-1519.

25 Para mayor información sobre estos acontecimientos véase el apartado "Els fets de Vinatea" en la obra BAydal SALA, Els orígens de la revolta.

26 Estos sucesos narrados tanto en la crónica de Pedro el Ceremonioso como en la de Zurita son refrendados, al menos en los aspectos generales relativos al destino de Lope de Concud, por la documentación de la cancillería. Si bien las fechas difieren sensiblemente entre las fuentes cronísticas y las cancillerescas, por lo que habría que atrasar el ajusticiamiento del caballero turolense hasta febrero-abril de 1331 . Vid. BAYDAL SALA, Els orígens de la revolta, pp. 45-57.
} 
sobre la escribanía morellana, puesto que en 1332 y luego en 1336 Pedro IV revocó las donaciones que habían realizado sus predecesores. Con todo, dos años después, el monarca atendió a las súplicas de Elvira López de Concud, hija de Lope de Concud, y le restituyó los derechos sobre las citadas escribanías en los mismos términos en los que Alfonso IV se la había entregado a su padre. ${ }^{27}$ Según las condiciones estipuladas, Elvira podía arrendarla a terceros por periodos limitados de tiempo, lo cual hizo en 1354 a nombre de Antoni Sanxo y Bartolomeo de Batea por siete años a un precio de 3.500 sueldos jaqueses. ${ }^{28}$

En 1346, Elvira y su marido, Juan Sánchez Muñoz, en vistas de la posible defunción de este por una enfermedad, decidieron redactar su testamento. La transmisión del patrimonio dentro de las familias de la aristocracia tenía gran importancia, ya que la fortuna familiar representaba su principal fuente de riquezas al renegar de los trabajos manuales. Además, se debe tener en cuenta que desde el siglo XIII surgió la idea del linaje, al cual quedaba adscrito ese peculio y no a una persona particular. ${ }^{29}$ Conjuntamente a estas ideas, se pasó de un sistema de transmisión cognaticio a uno de primogenitura agnaticia, que lateralizaba a las mujeres y los varones menores en la percepción de herencias. El perjuicio causado a parte de la descendencia se asumía como el precio a pagar para asegurar la reproducción económica familiar, pues de este modo se evitaban repartos que mermaban el peculio del grupo. Así mismo, el método agnaticio favorecía a los varones frente a las mujeres ya que lo normal es que sus hijos no tuvieran el apellido del linaje, lo que daría lugar a una alienación de los bienes con respecto al clan. ${ }^{30}$

Elvira López de Concud y Juan Sánchez Muñoz siguieron estos criterios a la hora de redactar su testamento, ${ }^{31}$ en el cual se diferencian dos heredades importantes: el señorío de Escriche ${ }^{32}$ y la Escribanía de Morella. El primer lote, más rico en cuantía y prestigio, estaba formado por el lugar de Escriche y todos los derechos señoriales que sobre él poseían. Este era para el hijo mayor, Gil, "a todos tiempos, sin contrariedat et embargo de los otros fijos nuestros et fijas, et hermanos suyos". Sin embargo, como la legislación aragonesa no permitía dejar a ningún vástago sin herencia, ${ }^{33}$ se establecía que de las rentas de esta heredad Gil debía dar a cada uno de sus hermanos ciertas cantidades en concepto de legítima; en concreto, tenía que entregar 3.000 sueldos jaqueses a Francisca para que le sirvieran de dote, 1.500 sueldos a cada una de sus hermanas menores, Sendina y Elvira, para costear su ingreso en una orden religiosa.

\footnotetext{
27 ACT, perg. 108, doc. 127.

28 Archivo Notarial de Morella, sig. 12, fol. 55v. Protocolo de Domingo de la Guerola.

29 Beceiro Pita y Córdoba de la Llave, Parenteco, poder y mentalidad, pp. 231-234.

30 WARD, "Noblewoman, family and identity", pp. 249-251 y GonZÁLEZ FERNÁNDEZ, "Las élites femeninas en las ciudades gallegas", pp. 356-357.

31 Archivo Histórico Provincial de Teruel, (en adelante AHPTE) Fondo Sánchez Muñoz-Dolz del Espejo, docs. 1 y 2. Consultada transcripción de: López Rajadel, Datación de la historia de los amantes de Teruel, p. 99.

32 A pesar de la confiscación de este señorío por Alfonso IV tras el ajusticiamiento de Lope de Concud, y su posterior entrega a García de Morillo (ACA, Cancillería, registros, nº 443, f. 139 r.), aquí volvemos a encontrarlo en manos de la hija de Lope.

33 Los Fueros de Aragón (según el ms. del Archivo Municipal de Miravete de la Sierra, Teruel), caps. 229 y 248. Ed. Gargallo Moya, Anúbar, Zaragoza, 1992, pp. 118-119 y 132.
} 
Tampoco se olvidan de los hermanos menores, los cuales recibirían 1.500 sueldos jaqueses con motivo de su casamiento tras cumplir los 20 años.

A estas disposiciones le sigue una extensa casuística en donde se establece quién sería el heredero en caso de que Gil muriese sin descendientes legítimos. En ese sentido, el señorío con todas sus pertenencias pasaría al segundogénito, Juan, y a sus descendientes, cláusula que se repite sucesivamente hasta llegar al cuarto y último hijo varón, Pedro. No obstante, en caso de fallecer Pedro no se recurre a la descendencia femenina, sino que en el texto se estipula que "Escrich finque a siempre en el mas cercano nuestro et de nuestro ynoio que sea fijo varon e de grado en grado finque de un heredero nuestro mas cercano en otro a siempre por todos tiempos". ${ }^{34}$

La escribanía de Morella, por el contrario, estaba destinada al segundogénito, Juan, acción que estaba dirigida a generar una segunda rama de este linaje. Este también debía colaborar junto con Gil en dotar a sus hermanos, aunque en menor cuantía: 500 sueldos jaqueses para cada uno de sus hermanos menores y otros tantos para su hermana Sendina, no así a Elvira, que veía su parte mermada con respecto a su otra hermana. Del mismo modo que había sido dispuesto para el señorío de Escriche, a esta determinación seguía una explicación acerca de a quién pertenecería la regalía morellana en caso de fallecer Juan sin descendencia legítima. Ahora bien, su sucesor directo era Gil, su hermano mayor y primogénito, quien se haría con el control de todo el patrimonio familiar. En caso de fallecer este también, el derecho sobre estas rentas pasaría al siguiente hermano vivo, pero si hubieran muerto los cuatro vástagos varones se establecía que la heredera de la escribanía sería Sendina, sin tener en cuenta a su hermana mayor Francisca. Tras lo cual no se dan más indicaciones precisas, sino que esta renta debía ser repartida, a partes iguales, entre los herederos más cercanos a Juan Sánchez Muñoz y Elvira López de Concud. Por más que toda esta reglamentación pueda parecer excesiva a veces se queda corta, puesto que el destino puede ser cruel y cebarse con una familia, tal y como les ocurrió a los hijos de Elvira López de Concud. El primero en fallecer fue el hijo primogénito, Gil, quien murió en 1356. Siguiendo las especificaciones del testamento paterno, el segundogénito, Juan Sánchez Muñoz, heredó el señorío de Escriche y la renta sobre la escribanía morellana..$^{35}$

El nuevo señor de Escriche disfrutó de la heredad durante una veintena de años, hasta su fallecimiento sin descendencia en $1374 .{ }^{36} \mathrm{~A}$ pesar de que no hemos podido encontrar evidencia escrita que certifique la defunción del resto de hermanos, fue Francisca quien

\footnotetext{
34 AHPTE, Fondo Sánchez Muñoz-Dolz del Espejo, docs. 1 y 2. Consultada transcripción de: LóPEz Rajadel, Datación de la historia de los amantes de Teruel, pp. 97-104.

35 Prueba de su nuevo título es que, desde esa fecha, en la documentación siempre se hace referencia a su estatus como señor de Escriche. Ejemplo de ello es su aparición en el listado de miembros de la cofradía de San Jorge que fundaron una misa diaria en honor de su patrón en la iglesia de San Miguel de Teruel en 1360 (Archivo del Capítulo General Eclesiástico, en adelante ACGE, perg. 125, doc. 148), o incluso en los documentos que firmó en 1369 como juez de Teruel, magistratura superior del concejo turolense (AHPTE, Concejo de Teruel, caja 1, doc. 706).

36 López RaJadel, Datación de la historia de los amantes de Teruel, p. 66.
} 
heredó las posesiones de su hermano, ${ }^{37}$ razón por la cual en 1376 encontramos en su poder todos los bienes especificados en el testamento. Si bien es posible que Elvira y Juan redactaran un testamento posterior que invalidara el firmado en 1346, resulta extraño que revocaran y cambiaran el uso del sistema de primogenitura agnaticia, hecho que sumado a lo extremadamente complejo que era desheredar a un hijo, ${ }^{38}$ hace que sea lógico pensar en la muerte de todos los hijos varones, y aun de Sendina, para entender cómo Francisca llegó a poseer toda la herencia.

Sea como fuere, Francisca Sánchez Muñoz llegó a ser la señora de Escriche y dueña de las rentas de la corte del justicia de Morella "por succession hereditaria descendient de don Lop de Concut, mi aguelo, la havia et por conseguient por succession hereditaria de don Johan Sanchez Munyoz et de donya Elvira Lopez, padre et madre quondam". ${ }^{39}$ Por otro lado, la nueva señora de Escriche se había desposado con Miguel Pérez del Roy, con quien había tenido dos hijos varones, Francisco y Juan Pérez del Roy, y una hija, Elvira López del Roy.

Junto a los testamentos y últimas voluntades, una de las principales herramientas usadas por los linajes dentro de sus estrategias familiares era el matrimonio. En un mundo en el que las uniones matrimoniales se regían por criterios racionales frente a irracionales como el amor, este sacramento se entendía como una forma de conseguir un acuerdo ventajoso basado en el capital simbólico y material de ambas familias. Así, lo que más importancia cobraba en estas uniones eran los intereses simbólico-políticos, unidos al aumento del patrimonio y el refuerzo o ampliación de alianzas. ${ }^{40}$ De ahí que la familia prefiriese un matrimonio hipergámico que beneficiase a la colectividad familiar sobre el individuo, para lo cual se sopesaban las diferentes opciones y se elegía al candidato más adecuado para favorecer al grupo en aspectos como el prestigio, la economía o una alianza; tal y como observa $\mathrm{M}^{\mathrm{a}}$ Carmen García Herrero en los matrimonios de la nobleza aragonesa del siglo $\mathrm{XV}^{41}$

Por estas razones no era extraño que se concertaran enlaces entre personas pertenecientes al mismo linaje; basten como ejemplo los desposorios entre Pedro Sánchez Muñoz, menor de días, y Muñoza Sánchez Muñoz en 1404. ${ }^{42}$ De forma similar actuó otro de los principales clanes de la oligarquía turolense, los Marcilla, quienes concertaron matrimonios entre las dos ramas del linaje, los Martínez de Marcilla y los Garcés de Marcilla, o incluso dentro de la misma rama familiar. ${ }^{43}$

\footnotetext{
37 AHPTE, Fondo Sánchez Muñoz-Dolz del Espejo, doc. 4.

38 Fueros Aragón, cap. 250. Ed. Gargallo Moya pp. 132-133.

39 ACT, perg. 241, doc. 280.

40 Bourdieu, El sentido práctico, pp. 302-303

41 GARCÍA HERRERO, Las mujeres en Zaragoza, p. 160.

42 ACGE, perg. 180, doc. 219.

43 Ejemplo del primer caso son los vínculos maritales forjados entre Pedro Martínez de Marcilla y Francisca Garcés de Marcilla o García Martínez de Marcilla y Juana Garcés de Marcilla, ambos de finales del siglo XIV (López RAJAdel, Datación de la historia de los amantes de Teruel, pp. 150 y 66-67 respectivamente). Mientras que para ilustrar los desposorios intrafamiliares basten como muestra las hermanas Catalina y
} 
En gran mayoría de las culturas, el matrimonio entre parientes cercanos es considerado tabú, lo cual encuentra sentido en los estragos que la sucesión de matrimonios endogámicos causa en la descendencia. En la Europa medieval, la capacidad de decidir si un matrimonio se podía llevar a cabo o no era detentada por la Iglesia, institución que también poseía el derecho de decidir cuándo esas normas podían saltarse, siempre previo pago, mediante una dispensa especial que aprovechaba la dualidad entre el cómputo de tradición germánica y romana. ${ }^{44}$ No obstante, el conjunto de reglas y prohibiciones establecido por la Iglesia se convirtieron es una herramienta a la hora de pactar estrategias matrimoniales, puesto que los linajes las usaron u obviaron según sus propios intereses y para su provecho. ${ }^{45}$

A pesar de esta posibilidad, la primera elección de marido para Elvira López del Roy debió de ser rechazada aun después de celebradas las nupcias y el matrimonio fue anulado, puesto que ella y Juan Sánchez Muñoz resultaron ser parientes en tercer grado.46 Tras este infructuoso intento de boda, Elvira volvió a casarse, esta vez con un miembro de una de las familias más importantes en el ámbito turolense del siglo XV, García Martínez de Marcilla. Llama poderosamente la atención semejante cambio con relación al pretendiente, puesto que el linaje de los Marcilla era enemigo acérrimo de los Sánchez Muñoz, con quienes tenían una guerra encubierta al menos desde $1309 .{ }^{47}$ Lo que es indudable es que la unión con el Marcilla era ventajosa, habida cuenta del peculio de su familia y del capital relacional que poseían, el cual les granjeaba cierta supremacía sociopolítica sobre otros linajes turolenses del momento.

De acuerdo con las costumbres de la época, los padres de Elvira firmaron una carta de constitución de dote con su futuro yerno, fechada en $1383 .{ }^{48}$ En este contrato, Francisca y Miguel se comprometieron a entregar a su hija una dote formada, en este caso, por la escribanía de Morella y sus aldeas, con todas sus rentas, frutos y emolumentos, además de joyas, ropas y útiles domésticos por valor de 600 sueldos jaqueses.

\footnotetext{
Constanza Martínez de Marcilla, casadas a principios del Cuatrocientos con Pedro y Martín Martínez de Marcilla respectivamente (AHPTE, Concejo, caja azul, carpeta 6, doc. 187)

44 En el IV Concilio de Letrán (1215) se estableció definitivamente la prohibición de contraer matrimonio entre familiares de hasta $4^{\circ}$ grado. Ahora bien, existía una disparidad entre la contabilidad de origen romano y la llamada germánica a la hora de establecer el grado de consanguineidad entre dos personas, circunstancia aprovechada para aprobar o denegar determinados enlaces. Vid. Goody, La evolución de la familia, pp. 132 y ss; Loring GARCiA, "Sistemas de parentesco", pp. 20-26.

45 Pastor de Togneri, "Estrategias de los poderes feudales", pp. 27-30 y García Fernández, "Vivir y morir en femenino en la Galicia", pp. 100-102.

46 López Rajadel, Datación de la historia de los amantes de Teruel, pp. 66-67.

47 Esta fecha marca el inicio de las hostilidades abiertas entre ambos bandos, lo cual no sería más que el preludio de una vorágine de violencia y atentados entre las dos familias que jalonó la vida en la ciudad y sus aldeas durante el resto de la Baja Edad Media (Ríos Conejero y Rodrigo Estevan, "La conformación de una élite urbana en el sur de Aragón", pp. 77-78). De estos conflictos se hacen eco las cuatro versiones de la crónica de la ciudad: López RAJADEL, Crónica de los jueces de Teruel, passim.

48 Estos pactos entre dos familias regulaban la vida futura de la nueva pareja, además, tenían fuerza legal y su contenido prevalecía sobre la legislación foral. Vid. García Herrero, "Las capitulaciones matrimoniales en Zaragoza en el siglo XV", pp. 382-385
} 
Con el fin de proteger estos bienes y evitar que salieran del patrimonio familiar, en el documento se especificaba que "non podades vender, arrendar ni transportar en otro senyorio alguno sino que siempre finque en la dita Elvira López o en suyos herederos" ${ }^{49}$. Así mismo, en caso de fallecimiento de Elvira, estas propiedades pasarían a sus descendientes legítimos o, en caso de no haberlos, retornarían a sus padres siempre que Elvira no hubiera testado. Para ello, se aseguraron de que García se comprometiera a devolver la dote, así como a establecer a su padre y tío como avalistas. Como se puede observar, el marido no tenía ningún derecho sobre la dote de su esposa, excepción hecha de una pequeña concesión: el disfrute de las rentas devengadas de la escribanía morellana en los tres años siguientes a la defunción de Elvira.

Estos acuerdos no se efectuaron de inmediato, puesto que en 1387 Juan I confirmó la posesión de la regalía de Morella a favor de Francisca Sánchez Muñoz. ${ }^{50}$ No sería hasta un año después que estos bienes fueron entregados a la nueva pareja, al mismo tiempo que se ratificaba la carta de donación, incluyéndose esta vez la renuncia expresa a esos bienes del hermano de Elvira, Francisco Pérez del Roy. ${ }^{51}$ Traspaso que fue confirmado por el rey Martín I el 13 de enero de $1400 .{ }^{52}$

Puede parecer extraño que Elvira no compartiera el cognomen de su padre ni sus hermanos, sino que vuelve a utilizar el de su abuela materna. Sin embargo, cambiar de apellido no era algo insólito en una época en la que las normas que rigen la forma de denominar a las personas todavía no estaban fijadas. Sánchez Saus, en su trabajo sobre la caballería sevillana, habla de diez razones por las que una persona se vería impelida a cambiar su apellido. ${ }^{53}$ No obstante, ninguna de ellas explica satisfactoriamente este caso concreto, ya que Elvira no abandonó su apellido, únicamente cambió la primera parte, Pérez por López, mientras que mantenía la segunda, del Roy, que la unía a su padre y hermanos.

Parece que, a través de esta permuta, Elvira buscaba manifestar su ascendencia materna, pero sin renunciar por ello al linaje de su padre, lo cual pone de manifiesto la conciencia de esta mujer de pertenecer a dos linajes. Seguramente el cambio estuviera motivado por la posesión de la escribanía y la importancia que esta renta poseía dentro de su patrimonio personal, herencia que provenía de su bisabuelo materno, Lope de Concud. Teoría que encuentra sustento en la idea expuesta por Isabel Beceiro y Ricardo Córdoba al hablar del papel de la mujer tras el triunfo del agnatismo, según la cual muchos segundones adoptaban el cognomen materno frente al paterno ya que el grueso de su

\footnotetext{
49 ACT, perg. 241, doc. 280.

50 ACT, perg. 256, doc. 302.

51 ACT, perg. 258 , doc. 305 y perg. 259 , doc. 306

52 ACT, perg. 295, doc. 344.

53 Las razones apuntadas por este autor son: ser el apellido una condición necesaria para poder recibir unos bienes; desafección para con la familia de origen; deseo de perpetuar el recuerdo de un antepasado; adoptar el cognomen de una persona hacia la que se le tienen relaciones de afecto derivadas de la crianza; tener el nuevo apellido mayor prestigio que el propio; cláusulas derivadas de pactos matrimoniales; que una rama de la familia quiera mostrar independencia con respecto al tronco principal del linaje; por conveniencia social; falta de arraigo del apellido familiar; y por último ilegitimidad de la persona al haber nacido fuera del matrimonio. Vid. SÁnchez SAus, Caballería y linaje en la Sevilla medieval, pp. 41-48.
} 
herencia procedía de la madre. ${ }^{54}$ Sin embargo, la falta de datos únicamente nos permite hacer suposiciones sobre por qué Elvira decidió usar el apellido de su abuela materna. Elvira no pudo disfrutar demasiado de la citada regalía, puesto que en 1407 García hizo donación a Miguel Martínez de Marcilla, primogénito tenido con Elvira, de gran parte de sus bienes, entre los que se encontraba la escribanía de Morella "con todos sus derechos gratias, privilegios, confirmaciones [...] et de las rendas et esdevenimientos de aquella en la forma et manera que yo las he possedido fasta el present dia de oy". ${ }^{55}$ Esto nos plantea una serie de dudas, dado que, como hemos visto, la dueña de esta regalía era Elvira y no su marido, a no ser que la donación únicamente hiciera referencia al derecho que tenía García a percibir la citada renta durante los tres años siguientes a enviudar. Por otro lado, en las negociaciones que llevó a cabo Gaspar Sánchez Muñoz por adquirir el señorío de Escriche en 1529 se especifica que García Martínez de Marcilla compró a los hijos de Francisco Pérez del Roy, hermano de su mujer, el señorío y los derechos sobre las escribanías, ${ }^{56}$ línea argumental seguida por Germán Navarro y José Antonio Martínez. ${ }^{57}$ No obstante, la venta del señorío se realizó en 1421, cuando García se hizo cargo de una importante deuda que sus sobrinos tenían a cambio de la cesión de Escriche..$^{58}$ Por ello, o se trata de dos ventas distintas con varios años de diferencia, o la escribanía llegó a García por otros medios, como herencia de su esposa, quien tenía libertad para legarla a quien quisiera.

En cualquier caso, esta regalía fue a caer en manos de Miguel, como hijo legítimo del matrimonio y heredero de ambos. No obstante, el traspaso incluía una nueva fórmula que buscaba ligar esta renta al linaje paterno y desvincularla de sus dueños tradicionales. Y es que todas las posesiones otorgadas a Miguel debían quedar en manos de

"vos et los vuestros descendientes que hayan el nombre el renombre de Marziella et sean a la honor del linaje de Marziella et si non se le contran fazer que non possidan nin possiddes las ditas heredades, antes aquellas haya, tenga e possida el present mas cerquano varon mio que haya el renombre de Marziella". ${ }^{59}$

La adhesión de la escribanía al nuevo linaje no fue bien acogida por la familia de Elvira, lo que llevó a su hermano mayor, Francisco Pérez del Roy, a querellarse con su cuñado García. Francisco apelaba a la cláusula del testamento de sus abuelos, Juan Sánchez Muñoz y Elvira López de Concud, en la cual se indicaba que este bien siempre debía estar en manos de herederos suyos para pedir la restitución de las rentas morellanas. El

\footnotetext{
54 Beceiro Pita y Córdoba de la Llave, Parentesco, poder y mentalidad, pp. 83-86.

55 ACT, perg. 313, doc. 362.

56 Biblioteca de Cataluña, ms. 234, ff. 82r-85v. Consultada transcripción de López RAJADEL, Datación de la historia de los amantes de Teruel, doc. 12, pp. 126-131.

57 Navarro Espinach, "Muñonez, Marcillas y otras familias dominantes en la ciudad de Teruel", p. 746; Martínez Martínez, El poder del dinero y el poder de las relaciones en el Antiguo Régimen, p. 40.

58 López RAJADEL, Libro del linaje de los Marcilla, pp. 24-28.

59 ACT, perg. 313 , doc. 362.
} 
pleito nunca llegó a la justicia ordinaria, sino que ambas partes decidieron recurrir a un arbitraje realizado por amigables componedores elegidos por ambas partes. ${ }^{60}$

No es infrecuente ver a miembros de la oligarquía hacer uso de estos métodos de justicia alternativos a los tribunales ordinarios, puesto que se trataba de mecanismos más flexibles, ágiles y baratos que los juicios tradicionales, sin perder la cobertura legal que estos ofrecían. Además, tenían la ventaja de poder adaptarse a cualquier contencioso puesto que los mediadores no tenían que seguir los parámetros marcados por la ley de forma estricta, lo que permitía soluciones que, en ocasiones, se apartaban de la tradición legal. ${ }^{11}$ Más aún, la elección de los árbitros quedaba en manos de los litigantes, por lo que escogían a personas cercanas que conocieran el motivo de la disputa y merecieran el respeto y confianza de ambos. No obstante, la existencia de intereses entre mediadores y contendientes, sumado a la diferente capacidad de los árbitros, podía poner en tela de juicio la equidad de las decisiones tomadas. Aun con todo, las posibilidades de llegar a acuerdos más beneficiosos que los que se lograrían por otras vías hacían que el recurso a estos arbitrajes se encontrase dentro de la estrategia planeada por alguno de los litigantes. Un ejemplo de todo este proceso es el descrito por Vicent Royo relativo a la disputa por el dominio útil de las escribanías de Vilafranca a mediados del siglo XIV. ${ }^{62}$ En cuanto al caso aquí estudiado, Francisco y García eligieron a un familiar cercano de cada uno, Antón del Roy y Miguel Martínez de Marcilla, quienes conocían bien la situación de los parientes en liza. Estos amigables componedores resolvieron que, en virtud de la documentación aportada, en especial la carta de dote de Elvira, ${ }^{63}$ la renta sobre la escribanía morellana pertenecería a García, y que Francisco debía renunciar a sus derechos sobre ella, por sí mismo y por sus herederos. A cambio, Francisco recibiría de García una serie de bienes inmuebles y el pago de 50 florines de oro, lo cual tenemos constancia que se realizó en varios pagos durante los días siguientes.

Por otro lado, García Martínez de Marcilla también hubo de llegar a un acuerdo con el otro hermano de su difunta mujer, Juan Pérez del Roy. Si bien en este caso consiguió que su cuñado renunciara a los derechos sobre la escribanía a cambio del pago de 1.000 sueldos jaqueses; retribución que nunca llegó a ser entregada, puesto que Juan y su mujer absolvieron a García del pago ese mismo año. ${ }^{64}$

La siguiente noticia que tenemos sobre la regalía, ya en manos de Miguel Martínez de Marcilla, hijo de García, está en los capítulos matrimoniales que este firmó con Catalina de Funes en $1422 .{ }^{65}$ En este acuerdo -al igual que en la constitución de dote que hemos

\footnotetext{
60 Si bien no conservamos la documentación original del pleito de 1418 (ACT, docs. 395-401), sí que ha llegado a nosotros un traslado realizado en 1430 en el cual se incluyen todos los documentos perdidos: ACT, perg. 368, doc. 442 .

${ }^{61}$ Royo PÉrez, "Árbitros y mediadores en el mundo rural valenciano”, pp. 381-382; RoYo PÉREZ, Els arrels històriques de la comarca dels Ports, p. 199.

62 Royo PÉrez, Vilafranca (1239-1412), pp. 109-238.

63 ACT, perg. 256, doc. 302.

64 ACT, perg. 338, doc. 403.

65 ACT, perg. 345, doc. 411. Consultada transcripción de LóPEz RaJADEL, Datación de la historia de los amantes de Teruel, doc. 5, pp. 110-112.
} 
visto con anterioridad- se establecían los términos económicos relativos al matrimonio, si bien en esta ocasión se hacía según costumbre de Valencia. En este sentido, Catalina aportaba una dote de 1.000 florines, cantidad que Miguel aumentaba en otros 500, obligándose él y su padre a devolver la cantidad íntegra a la esposa o a sus progenitores "in omni casu et evento dotis restituendi". Con el fin de dar mayor seguridad a su palabra, Miguel y García obligaban sus posesiones, en especial la escribanía de Morella, aceptando que en caso de no restituir a la novia su dote, sus posesiones serían subastadas. Además, para esta cláusula en concreto, el futuro marido y su avalista renunciaban al fuero de Valencia, normativa a la que se adscribía el resto del texto, y aceptaban el fuero de Teruel, por lo que sería el juez de Teruel y no la justicia valenciana quien incautaría los bienes y realizaría la almoneda.

No se trató de una cláusula baladí, puesto que el matrimonio resultó infructuoso y Catalina reclamó la devolución de los 1.500 florines que le correspondían. La demanda quedó sin respuesta por lo que la afectada recurrió al juez de Teruel, quien hasta en tres ocasiones exigió al Marcilla que cumpliese con su palabra, mas al no ser satisfecha la petición, el 7 de julio de 1446, procedió a embargar la propiedad y ponerla en subasta pública. ${ }^{66}$ Como consecuencia de esta intervención judicial, el derecho sobre las escribanías morellanas fue vendido a Francisco López de Monreal a cambio de 7.600 sueldos jaqueses, que revirtieron en Catalina. ${ }^{67}$

Sin embargo, Francisco López de Monreal no disfrutó durante mucho tiempo de su compra, visto que medio año después las cedió a Catalina a cambio de la devolución de la cantidad que había pagado por ellas. ${ }^{68}$ A pesar de que no conservamos documentación que atestigüe relación entre estas dos personas, ${ }^{69}$ la celeridad de la cesión por la misma cantidad parece indicar que se trataba de un acuerdo previo que permitía a Catalina poseer el derecho sobre las escribanías, situación que su marido, a juzgar por sus reiteradas negativas, intentó evitar. En cualquier caso, esta maniobra permitió que la regalía permaneciera en la familia y que, tras Catalina, esta pasase a sus hijos: García, el de la Aldehuela, ${ }^{70}$ y Gonzalo Martínez de Marcilla.

\footnotetext{
6 ACT, perg. 394, doc. 470

67 ACT, perg. 397, docs. 474 y 475

68 ACT, perg. 398, doc. 476.

69 Por más que en el AHPTE se conservan varios documentos de Francisco López de Monreal, estos son los protocolos notariales derivados de su trabajo como notario público y notario del concejo y de fechas más tardías, por lo que a partir de ellos no podemos inferir una posible relación amistosa entre él y Catalina.

70 Si bien autores como Germán Navarro y Concepción Villanueva (Navarro Espinach, "Muñonez, Marcillas y otras familias dominantes en la ciudad de Teruel”, p. 746; Navarro Espinach y Villanueva Morte, “Gil Sánchez Muñoz (1370-1447)”, pp. 243-245) interpretan que este personaje gozó de la posesión de las escribanías de Morella y del señorío de Escriche, esto es un error inducido por lo homonimia de este clan. Gracias al manuscrito 234 de la Biblioteca de Cataluña sabemos que se trata de dos personas distintas: García Martínez de Marcilla, apodado el de la Aldehuela, dueño de la escribanía, y su primo del mismo nombre, canónigo de Santa María de Mediavilla de Teruel, quien ostentó el señorío de Escriche hasta 1525 .
} 
Los hermanos disfrutaron de la renta morellana a partes iguales hasta 1476, momento en el que Gonzalo vendió su parte a García por 7.500 sueldos jaqueses. ${ }^{71}$ Con todo, no será hasta principios de la centuria siguiente, en 1515, cuando el soberano, Fernando II, ratifique la donación que sus antecesores hicieron de la escribanía de Morella a los descendientes de Lope de Concud, en este caso en la figura de García. ${ }^{72}$ Real privilegio que fue confirmado tres años más tarde por los reyes Juana y Carlos. ${ }^{73}$

Este Marcilla, apodado el de la Aldehuela, sería el último de este linaje en ostentar los derechos sobre esta concesión real, ya que él mismo la enajenó en favor del cabildo de la entonces colegiata de Teruel. En otras palabras, García hizo caso omiso de la voluntad de su abuelo paterno de vincular esta renta a su apellido y en 1518 testó en favor del cabildo de Santa María de Mediavilla, a cambio de que estos religiosos realizaran una misa diaria por su alma. ${ }^{74}$ Ahora bien, las rentas no pasarían al cabildo hasta la muerte de su esposa, Violante Cubells, quien las poseería en usufructo tras el deceso de García. Aunque en un principio el testamento supuso problemas legales entre la Iglesia turolense y la Corona, una sentencia dada en Valencia en 1519 vino a ratificar las últimas voluntades de García Martínez de Marcilla, por lo que la escribanía de Morella y sus aldeas pasó a engrosar las rentas de la futura catedral de Teruel. ${ }^{75}$

\section{Conclusiones}

A lo largo de estas páginas hemos seguido el recorrido de las rentas percibidas de la regalía de la escribanía del justicia de Morella y de sus aldeas a lo largo de seis generaciones, desde su cesión por Alfonso IV a Lope de Concud hasta su integración en el patrimonio de la iglesia de Santa María de Mediavilla. A pesar de que la documentación conservada no ha permitido determinar el peso de estos ingresos en relación con la hacienda total de sus beneficiarios, las cantidades obtenidas no eran baladíes lo que, sumado a su simbolismo, explica la significación que tenían para el linaje estudiado. Gracias a ello, se ha podido observar la importancia que la oligarquía bajomedieval

\footnotetext{
$71 \quad$ ACT, perg. 432, docs. 522 y 523.

72 ACT, perg. 485, doc. 597.

73 ACT, perg. 496, doc. 615.

74 ACT, perg. 499, doc. 619.

75 Tal y como se explica en la sentencia, esta cláusula testamentaria era contraria al fuero de Valencia, en donde se especifica que estaba prohibido alienar, vender o transferir regalías a instituciones eclesiásticas, y, en caso de hacerse, la Iglesia debía pagar el derecho de amortización. Al tratarse de una regalía sobre un territorio valenciano, el lugarteniente del tesorero general de los reyes, Alfonso Sanchís, abrió una causa contra la colegiata turolense, por la que exigía el pago de 375 libras valencianas a cambio de la posesión de la regalía. No obstante, los eclesiásticos turolenses se escudaron en que el testador era turolense y por tanto se debían acoger a las costumbres aragonesas, en donde no se concebía ese resarcimiento a la Corona. El resultado final, dado por el propio Alfonso Sanchís, fue que el cabildo de Santa María de Mediavilla pudiera poseer las escribanías morellanas, a pesar de que esto fuera contrario a la legislación valenciana. ACT, perg. 499, docs. 618-619.
} 
daba a la conservación del patrimonio dentro de un linaje, así como los métodos usados y la función activa que las mujeres desempeñaban en la consecución de ese objetivo.

Entre las estrategias principales estaba el establecimiento de sistemas de primogenitura agnaticia, la cual favorecía al primogénito varón y, en ocasiones, a un segundo hijo al que se entregaba otro conjunto patrimonial menor que generaba una rama secundaria de la familia. Esto suponía la lateralización de mujeres e hijos menores en el acceso a la herencia familiar, en aras de garantizar la reproducción económica y social del linaje. Igualmente, se recurría a disposiciones que adscribían el patrimonio a un linaje. Como se ha podido observar, tanto los testamentos como las constituciones de dote incluían cláusulas que vinculaban los bienes a un determinado apellido, estableciendo que en caso de no haber descendientes legítimos, la heredad debía recaer sobre gentes pertenecientes al linaje de origen.

Este sistema de transmisión de la propiedad era el fruto de un consenso entre los distintos grupos de parentesco, mediante el cual se buscaba asegurar la fortuna familiar tanto por vía paterna como materna. Lo que incluso llegó a influir en el cognomen adoptado por algunas personas, pues hubo quien prefirió mantener el matronímico como símbolo de unión al patrimonio derivado de la rama materna. Caso de Elvira López del Roy, que cambió la primera parte de su apellido para indicar su ascendencia materna, de donde procedía la mayor parte de su peculio, pero sin renunciar a mantener la segunda parte del cognomen que la ligaba a su padre y hermanos.

No obstante, también se ha podido comprobar cómo, pese a todas las medidas tomadas, el patrimonio a veces cambiaba de linaje a causa de los pactos matrimoniales realizados. Hecho que podía ser motivo de malestar entre los miembros del linaje originario, quienes en muchos casos llegaron a presentar querellas contra sus familiares políticos. Para ello no dudaron en recurrir a los tribunales o a métodos de infrajusticia que permitían una mayor versatilidad y alcanzar acuerdos más equitativos.

Por otro lado, se ha comprobado que las mujeres conservaban la hacienda familiar en el contexto de su propia generación, la gestionaban y sacaban rédito de la misma; muestra de ello son los negocios de Elvira López de Concud con notarios valencianos, a quienes arrendaba la explotación de la escribanía del justicia de Morella. Administración que no era estorbada por miembros masculinos de su linaje y, además, podían transmitir sus bienes a la siguiente generación sin ver perjudicados sus derechos por sus maridos. $\mathrm{Al}$ mismo tiempo, mujeres como Catalina de Funes no dudaron en denunciar a sus propios cónyuges con el fin de proteger su dote y asegurar un legado a su descendencia. 


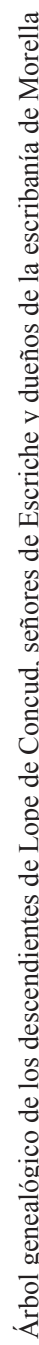

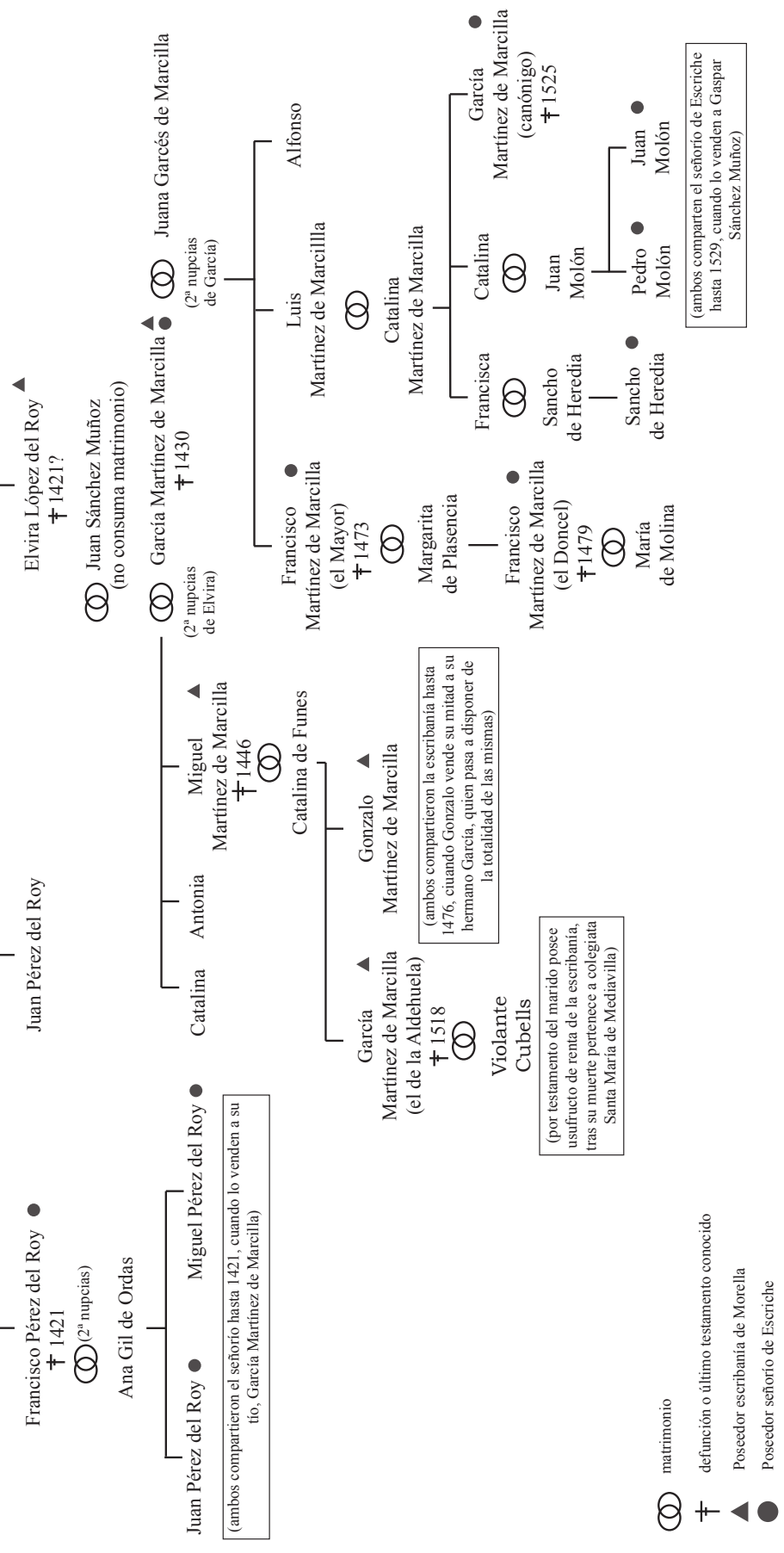




\section{Bibliografía}

Baydal Sala, Vicent, Els orígens de la revolta de la unió al regne de València (13301348), Publicaciones Universidad de Valencia, Valencia, 2013.

Beceiro Pita, Isabel y Córdoba de la Llave, Ricardo, Parentesco, poder y mentalidad. La nobleza castellana siglos XII-XV, CSIC, Madrid, 1990.

Bourdieu, Pierre, El sentido práctico, Siglo Veintiuno, Buenos Aires, 2007.

Cabanes Pecourt, María de los Desamparados, Documentos de Jaime I relacionados con Aragón, Institución Fernando el Católico, Zaragoza, 2009.

Conde-Francisco Gimeno, Rafael, "Notarías y escribanías de concesión real en la Corona de Aragón (s. XIII)", Notariado público y documento privado: de los orígenes al siglo XV. Actas del VII Congreso Internacional de Diplomática. Vol. 1, Generalitat Valenciana, Valencia, 1989, pp. 281-331.

Díez SÁnchez, Marta, "La escribanía de la sala del Consell: un oficio controvertido", Revista de Historia Moderna, 17 (1998-1999), pp. 311-320.

García Fernández, Miguel, "Vivir y morir en femenino en la Galicia de los siglos XIV y XV", Mujeres con poder en la Galicia medieval (siglos XIII-XV). Estudios, biografías y documentos, Eduardo Pardo de Guevara y Valdés (ed.), Instituto de Estudios Gallegos, Padre Sarmiento, Santiago de Compostela, 2017, pp. 71-239.

García Fernández, Miguel, "Las élites femeninas en las ciudades gallegas de la Baja Edad Media", Mirabilia: Revista Electrónica de História Antiga e Medieval, 17 (2013), pp. 337-393.

García Herrero, $\mathrm{M}^{\mathrm{a}}$ Carmen, Las mujeres en Zaragoza en el siglo XV, Ayuntamiento de Zaragoza, Zaragoza, 1990.

García Herrero, "Las capitulaciones matrimoniales en Zaragoza en el siglo XV", En la España medieval, 8 (1986), pp. 381-398.

Gargallo Moya, Antonio, Los Fueros de Aragón (según el ms. del Archivo Municipal de Miravete de la Sierra, Teruel), Anúbar, Zaragoza, 1992.

Garrido Medina, Luis, y Gil Calvo, Enrique, "El concepto de estrategias familiares", Estrategias familiares, Luis Garrido Medina y Enrique Gil Calvo (eds.), Alianza, Madrid, 1993, pp. 13-34.

Godelier, Maurice, Lo ideal y lo material, Tecnos, Madrid, 1989.

Goody, Jack, La evolución de la familia y el matrimonio en Europa, Herder, Barcelona, 1986.

Harries, Marvin, El desarrollo de la teoría antropológica, Alianza, Madrid, 1978.

LAFUENTE GómEz, Mario, “Amistad y poder entre la baja nobleza aragonesa del Trescientos", Mundos medievales. Espacios, sociedades y poder, Beatriz Arízaga Bolomburu et al (eds.), PUbliCan, Santander, 2012, pp. 1509-1523. 
López Rajadel, Fernando, Crónica de los jueces de Teruel (1176-1532), Instituto de Estudios Turolenses, Teruel, 1994.

López Rajadel, Fernando, Datación de la historia de los amantes de Teruel. A través de los datos socioeconómicos del "papel escrito de letra antigua” copiado por Yagüe de Salas, Fundación Amantes, Teruel, 2008.

López Rajadel, Fernando, Libro del linaje de los Marcilla, señores de Escriche, Instituto de Estudios Turolenses, Teruel, 2016.

LORING GARCíA, Ma Isabel, "Sistemas de parentesco y estructuras familiares en la Edad Media”, La familia en la Edad Media, José Ignacio de la Iglesia Duarte (coord.), Instituto de Estudios Riojanos, Logroño, 2001, pp. 13-38.

Martínez Martínez, José Antonio, El poder del dinero y el poder de las relaciones en el Antiguo Régimen: La trayectoria familiar de los Muñoz de Otálora, tesis doctoral inédita, Universidad de Murcia, 2017.

Navarro Espinach, Germán, "Muñoces, Marcillas y otras familias dominantes de Teruel (1435-1500), Anuario de Estudios Medievales, 32/2 (2002), pp. 723-776.

Navarro Espinach, Germán y Villanueva Morte, Concepción, “Gil Sánchez Muñoz (1370-1447), el antipapa Clemente VIII. Documentación inédita de los archivos de Teruel”, Revista de Historia Medieval, 15 (2006-2008), pp. 239-254.

PAStor de Togneri, Reyna, "Las estrategias de los poderes feudales: matrimonio y parentesco", Historia de la mujer e Historia del matrimonio, M ${ }^{\mathrm{a}}$ Victoria López Cordón y Montserrat Carbonell Esteller (eds.), Universidad de Murcia, Murcia, 1997, pp. 25-35. RÁBAde Obrado, María Pilar, "Las lugartenencias de escribanías como conflicto: un ejemplo de la época de los Reyes Católicos, Espacio, Tiempo y Forma. Serie III Historia Medieval, 5 (1992), pp. 211-228.

Ríos Conejero, Alejandro y Rodrigo Estevan, María Luz, "La conformación de una élite urbana en el sur de Aragón. Los caballeros villanos”, Bajar al reino. Relaciones sociales, económicas y comerciales entre Aragón y Valencia: siglos XIII-XV, Esteban Sarasa Sánchez (coord.), Institución Fernando el Católico, Zaragoza, 2017, pp. 63-80. Rodríguez Llopis, Miguel, "La escritura y el poder. La emisión de documentos en la sociedad murciana bajomedieval", Áreas: Revista internacional de Ciencias Sociales, 9 (1988), pp. 11-24.

Royo PÉrez, Vicent, Vilafrancaa (1239-1412). Conflictes, mediacions de pau i arbitratges en una comunitat rural valenciana, Castellón de la Plana, Universidad Jaume I, 2016. Royo PÉREz, Vicent, Els arrels històriques de la comarca dels Ports. Societat, poder $i$ identitat en una terra de frontera durant la Baixa Edat Mitjana, Benicarló, Onada ed., 2018.

Royo PÉrez, Vicent, “Árbitros y mediadores en el mundo rural valenciano durante la Baja Edad Media”, Espacio, tiempo y forma. Serie III Historia medieval, 32 (2019), pp. 379-412. 
Sánchez Adell, José, "La Comunidad de Morella y sus aldeas durante la baja Edad Media (Notas y Documentos), Estudis Castellonencs, 1 (1983), pp. 73-184.

SÁnchez SAus, Rafel, Caballería y linaje en la Sevilla medieval. Estudio genealógico y social, Diputación de Sevilla, Sevilla, 1989.

Verdés Pijuan, Pere y Guinot Rodríguez, Enric, "Escrivania", Voz en el Glosario crítico de fiscalidad medieval, Institución Mila i Fontanals, http://www.1minut.info/ glosariofiscalidad.org/wp/?page_id=41, [fecha de consulta: 20 julio 2020].

WARD, Jennifer, "Noblewoman, family and identity in Later Middle Europe", Nobles and nobility in Medieval Europe. Concepts, origins, transformations, Anne Duggan (ed.), The Boydell Press, Woodbridge, 2000, pp. 245-263. 